\title{
The Potential use of Semiochemicals in Pest Suppression
}

\author{
Palial $S^{*}$ and Nidhi \\ Department of Entomology, Dr. Yashwant Singh Parmar University of Horticulture \\ and Forestry, India
}

*Corresponding author: Shivani Palial, Ph.D, Research Scholar, Department of Entomology, College of Horticulture, Dr.Yashwant Singh Parmar University of

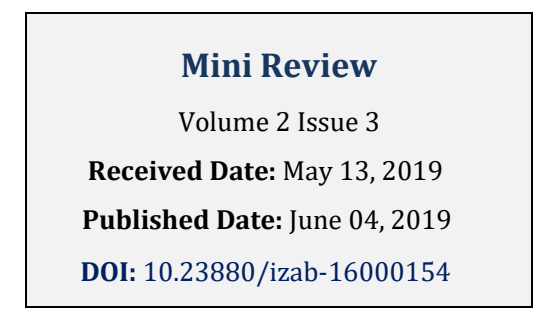
Horticulture and Forestry, Solan, H.P, India, Tel: 9815468570; Email: spalial33@gmail.com

\section{Abstract}

Semiochemicals are natural substances produced and used by insects and plants to communicate. The different Semiochemicals based insect management techniques, such as monitoring, mating disruption, mass trapping, attractant, repellent, and push-pull strategies are highlighted. Semiochemicals are divided into two groups naturally secreted (pheromones and allelochemicals) and not secreted (attractants, disrupt ants, repellents, and other Para pheromones). Pheromones include sex, aggregation, alarm and trail pheromones, etc. Monitoring of insects can be done either with kairomones or pheromones baits traps. Mass trapping aims at catching a substantial proportion of the pest population before mating, oviposition or feeding and thus preventing damage to the crop. Mating disruption technique is achieved by the widespread application of synthetic pheromones. The push-pull strategy involves behavioral manipulation of insect pests and their natural enemies by the integration of stimuli that act to make the protected resources unattractive, while luring them towards an attractive resource, from where the pest is subsequently removed. Methods for crop protection based on Semiochemicals show advantages over method based on conventional insecticides. Semiochemicals are considered safe and environmentally friendly molecule due to their natural origin, low persistence in the environment and species-specific, which attribute much to their harmless effect on non-target organisms. However, there are some difficulties in the practical application of Semiochemicals in pest suppression; therefore, applications of Semiochemicals for insect pest management have, however, been limited.

Keywords: Semiochemicals; Mating Disruption; Mass Trapping; Repellent; Puss-Pull Strategy; Pest Suppression

\section{Introduction}

Insect's behavior is mediated by the wide range of chemicals. They use these chemicals to their own advantage to attract pest to trap, repel them from their native place. In broad term, these chemical compounds known as the Semiochemicals. Semiochemicals (Gk. semeion or signal) are the chemicals that mediated the interaction between the organisms [1]. They are released by one individual and evoke a behavioral or physiological response in other individuals. The insects use Semiochemicals to mediate important behaviors such as mating, oviposition, and foraging for resources [2]. The attraction of insects to plants and other host organisms involves the detection of specific Semiochemicals or specific ratios of Semiochemicals [3]. For pest 
management, use of the Semiochemicals a non-toxic intervention is an eco-friendly alternative that influences the behavior of pest insects. Attractants can be used in baited traps to monitor pest populations. Furthermore, Semiochemicals that repel pests or attract their natural enemies could be used to keep pest populations below damaging levels.

A Semiochemicals is divided into two groups' pheromones, which act within the same species (intraspecific interactions) and allelochemicals, which act between the species (interspecific interactions). Further, allelochemicals are chemicals that are significant to individuals of a species different from the source species. Allelochemicals mediate the interaction between different species and this interaction may be favorable to the emitter (allomones), or the benefit to the receiving organism (kairomones), or both (synomones) [4]. Pheromones (Gk. phereum, to carry; hormone, to excite or stimulate) are released by one individual of a species that evoke the behavior and physiological response in another individual of the same species. Pheromones consist of sex, aggregation, alarm or territory making signals that evolved for the communication on the basis of interaction of member of the community.
However, perceived ill effects associated with the use of broad-spectrum insecticides have precipitated global efforts towards finding alternate pest management strategies. The Semiochemicals are not, however, direct alternatives for chemical insecticides, being used not as killing agents but perform as monitoring tools to improve the timing of conventional chemical controls [5]. The indiscriminate use of pesticides can be minimized by using Semiochemicals, a tool that can be applied in the field to manage pest and their natural enemies [6]. Semiochemicals can help to satisfy the public demand for an environmentally benign alternative because the number of Semiochemicals released into the environment in relatively minute amounts, and are relatively non-toxic to vertebrates, highly species specific to target insect. Here, we reviewed the different ways in which Semiochemicals have been used in pest suppression to till date, using some selected examples based on the research by the workers (Figure 1). Limitations to their use are also considered along with possible ways in which these limitations may be overcome in the future. The major goal of pest suppression is to monitor the pest population and to alter the behavior of insects and their natural enemies.

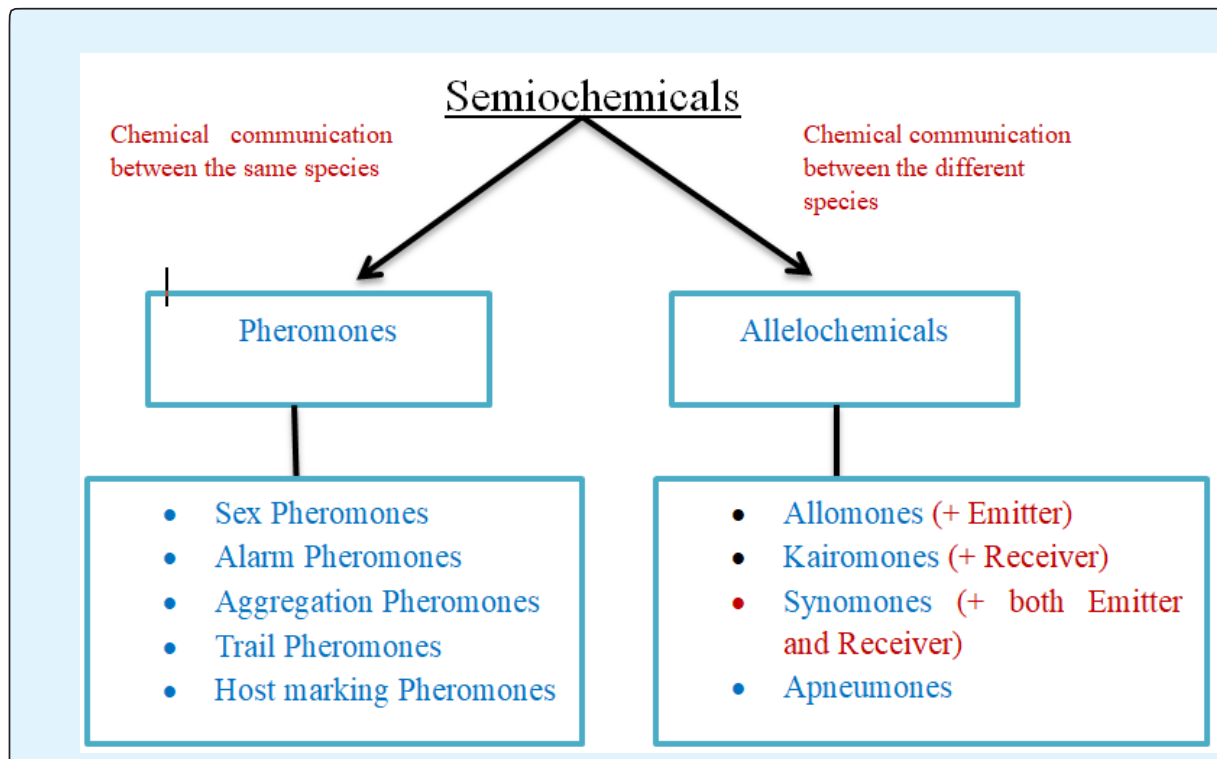

Figure 1: Classification of Semiochemicals.

\section{Strategy for use of the Semiochemicals in the Pest Suppression}

The most successful approach using the Semiochemicals in the pest suppression is to monitor the pest population activity or to determine the number of an insect population to take the necessary need base control measure. A large number of synthetic pheromones are released into the crop to prevent or delay the mating and hence reduce the incidence of an insect in the next 
generation. Mass trapping is considered most effective for suppressing and eradicate the low density and isolated pest population. The main purpose of mass trapping is to catch the insect to remove a large number of insect populations from a source before mating, oviposition or feeding and thus preventing damage to the crop.

\section{Monitoring}

The successful practical application of Semiochemicals is in monitoring the presence and abundance of pest population [7]. The monitoring system is helpful in making the decision of control measure to keep the pest population below the economic threshold level. It can be done either with kairomones or pheromones baits traps. Kairomones based tarps have most commonly used to monitor the biological control agent Rhizophagus grandis, a predator of spruce bark beetle Dendroctonus micans population [8]. Pheromones bait traps especially the sex pheromones are effective in monitoring the insects than kairomones because of strong attractant and speciesspecific nature of pheromone attraction [9]. Pheromones based monitoring system can be used to assess the abundance and trends of population or to the damage caused by the insect pests. Thresholds of the catch are determined on the basis of the magnitude of trap captures, either for the timing or for making the decision whether or not control measure is to be taken [10]. Currently, pheromone lures are used in traps to monitor many different crop pest species. These pheromones traps are used to detect the low-density population, and also for monitoring the presence of invasive species and prevent its establishment and spread [11]. In the stored grain pest, multiple pheromones in a single trap are a new trapping system for monitoring the behaviour of different species. Sex pheromones for Ephestia cautella (Walker), E. kuehniella, Plodia interpunctella, Trogoderma granarium (Everts) and aggregation pheromones for Tribolium castaneum and Tribolium confusum are incorporated into natural food attractant oils for capturing in the trap [12].

\section{Mating Disruption Strategy}

Mating disruption is a technique by which synthetic sex pheromones are dispensed into the pest habitat in a sufficient amount to reduce the ability of a male to locate the female and thereby affecting the organism's chance of reproduction [13]. Attractant insect pheromones, such as sex and aggregation pheromones are species-specific Semiochemicals signals that have been identified and successfully in many insect pest management programmers across the world [14]. Mating disruption by use of sex pheromones has been successfully implemented within pest management programs for many species of pest, especially Lepidoptera pest of fruits, vegetables, and forest $[15,16]$. Reported the important successes of mating disruption include control of the codling moth, Cydia pomonella in pome fruit, the oriental fruit moth, Grapholita molesta in stone fruit like peaches and nectarines, the tomato pinworm, Keiferia lycopersicella in vegetables, the pink bollworm, Pectinophora gossypiella in cotton, and the omnivorous leafroller Platynota stultana in vine yards. In India, mating disruption using a blend of Z-9-hexadecenal, Z-11hexadecenal and Z-9-octadecenal in a polyvinyl chloride (PVC) resin formulation was found to be effective [17]. To control the sugarcane borer, C. sacchariphagusindicus, uses a pheromone blend of Z-1-octadecenal and Z-13octadecenol [18].

\section{Mass Trapping Strategy}

Mass trapping has been used to manage a wide range of insect pests, typically in lepidoptera, coleopteran, and dipteran. The concept of mass trapping includes the use of synthetic pheromones such as sex and aggregation pheromones, and a food and host attractant, bait traps, to control of the insect population suppression and eradication. To achieve this, traps have to capture a large proportion of the population in an area, before mating or oviposition, and retain or kill captured individuals. The lure must be more effective than natural sources of attraction such as mates or food/oviposition sites and ideally retain efficacy over the entire period of adult insect reproductive activity to reduce damage to a minimum. Successful mass trapping for pest suppression varies according to the semiochemicals used. In the Coleoptera, the bark beetle, Ips spp. and Dendroctonus spp. (Curculionidae: Scolytinae) produce the aggregation pheromones, which attract both sexes about equally and thereby provide an opportunity to reduce the pest population as a whole and similarly in pest weevils, e.g. the boll weevil, Anthonomus grandis, the palm weevils, Rhynchophorus spp. (Curculionidae) and the banana weevil, Cosmopolites sordidus (Dryophthoridae) [19,20]. In Lepidoptera, the female typically releases a speciesspecific sex pheromone that only attracts males. Due to the males' capacity for multiple mating, a very large proportion of the male population has to be removed before female fecundity is reduced. The underlying behavioral mechanism is competitive attraction between calling females and discrete pheromone point sources, the latter resulting in the permanent removal of potential mates [21]. Control of the brinjal fruit and shoot borer moth, Leucinodes orbonalis, has been achieved due to a combination of a reduction in the pest population and a 


\section{International Journal of Zoology and Animal Biology}

greater impact of natural enemies, numbers of which increased after cessation of the use of insecticides [22].

\section{Attractant}

Attract and kill technique includes the use of Semiochemicals to lure an insect to a source that contains a killing agent and lead to the reduction of the insect population by killing the target insect or reducing its fitness. Plants have evolved so many ways of defending themselves against insect attack, including through emission of defense volatiles. These volatiles serve the plants defense by directly repelling phytophagous insects and/or indirectly through attracting natural enemies antagonistic to the herbivores [23]. Semiochemicals use in attract and kill are pheromones (e.g., sex pheromones), kairomones (e.g., host volatiles), attractants with a known behavioral function (e.g., host plant or oviposition odours), and attractants identified through the screening of candidate chemicals with poorly known behavioral functions. Appropriate plants were discovered that naturally emit signaling chemicals (Semiochemicals) [24]. It was reported that the use of lure and kill for the pest management of pink bollworm, Egyptian cotton leafworm, codling moth, apple maggot, biting flies, and bark beetles or the eradication of invasive species e.g., tephritid fruit flies and boll weevils [25].

\section{Repellent}

Repellent is a substance that inhibits or deter the insects from finding, feeding or oviposition on the host. In pest suppression, repellent is to create an odor barrier to prevent an arthropod from entering a space occupied by a potential host, as a 'safe zone' to reduce encounters between the insect and the host [26]. Semiochemicals with the repellent effect is used for the control of the agricultural important pest. Essential oils likes' citronella oil, pine oil has been found to have repellent or oviposition deterrent properties against some insects. DEET is considered the most effective commercial repellent available and is used primarily to repel hematophagous insects. Petroleum spray oils to cotton may have a deterrent effect, suppressing oviposition of Helicoverpa spp. on these plants [27]. Allelochemical, pentadecanal, has exhibited the oviposition deterrent against the stem borer, Chilo suppressalis.

\section{Push Pull Strategy}

Push-pull is a pest suppression strategy that combines the repellent and attractant Semiochemicals to manipulate the pest and their natural enemies [28]. Pushpull strategy for the pest suppression is a newly emerged pest control method which uses non-toxic components for pest population reduction with reduced pesticide input [29]. The Push-pull strategy uses the Semiochemicals for behavioral manipulation of insect pests and their natural enemies employing the integration of insect stimuli which makes the protected resource unpalatable and unattractive to the pests (push component) while luring them towards a more attractive source (pull component) and where the pests can be removed. The push component which is an intercrop or trap crop grown around the perimeter of the main crop. The main crop is protected by cues that reduce the pest colonization and development that is a push effect [30]. These cues are the Semiochemicals particularly kairomones which repel the pests and drive them away from the main crop [31]. It was reported that the Napier grass was planted as a border and the intercrop along with the main crop for suppression of stem borer infestation [32]. Napier grass has properties to secrete the volatile which is acting as the oviposition attractant for the gravid stem borer adult female. Push-pull system was tested in management of fall armyworm, Spodoptera frugiperda in maize crop, maize crop is protected by Semiochemicals that are emitted by the intercrop, Desmodium intortum that repel the stem borer moths while the cues released by the border crop, Brachiaria pull them. There is a reduction in $82.7 \%$ larvae per plant and $86.7 \%$ in plant damage per plot were observed in push-pull adopted plot and also significantly higher yield, 2.7 times, of maize crop was observed compared to maize monocrop plots [33]. Pushpull strategy also found to be effective in controlling the insect vectors like Anopheles arabiensis (vector of malaria) and tsetse flies (vector of sleeping sickness) (Figure 2). Several kairomones are identified from the hosts for large scale suppression of their vectors.

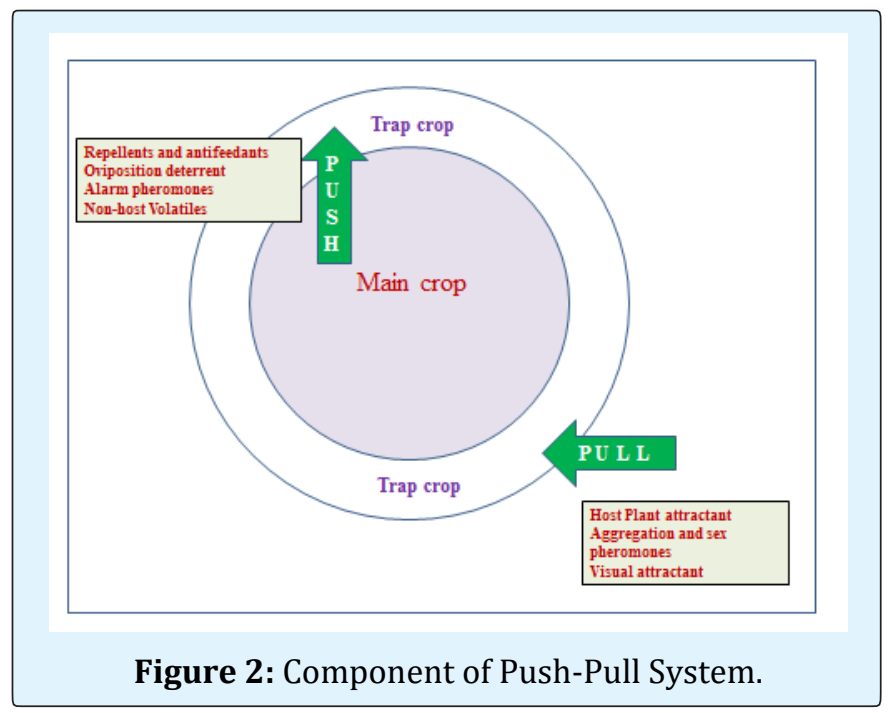




\section{International Journal of Zoology and Animal Biology}

\section{Conclusion}

Semiochemicals have a potential role in insect pest suppression by using the number of management strategies. These include the monitoring and detection, mating disruption, mass trapping, attract and kill repellent techniques. Monitoring is considered as an efficient tool for making the decision of control measure. Mating disruption by use of pheromones is a successful strategy for the control of the pest. Recently, the most common use of Semiochemicals is to attract, trap and kill the insect-pest. Many research findings have been found the practical use of Semiochemicals for monitoring and pest suppression but are not yet widely used. To understand the role of Semiochemicals in pest suppression, in addition, to studying the behavior interaction of host-insect- natural enemies, we should able to clarify the origin of these chemical cues. New sights for production of the behavior modifying chemical signal will reveal the specific target and disturb the behavior of insect-pest. Proper understanding of biochemical, molecular and behavioral ecology of plantinsect interactions is essential to develop similar novel and sustainable insect pest management strategies. Recent advances in molecular access will open the new door in the study of the role of Semiochemicals for future application of pest suppression. There is a need for more efficient technology method for the application of the control method based on Semiochemicals. However, we must obtain a sound ecological understanding to accompany advances in the fields of chemistry, biochemistry, physiology, and genetics. Semiochemicalsbased alternatives are urgently needed to replace inefficient or health-hazardous methods for pest control. The use of behavior modifier as a tool shows promising results, and it is worthwhile continuing the development of such a tool.

\section{References}

1. Dicke M, Sabelis MW (1988) Infochemical terminology: based on cost-benefit analysis rather than origin of compounds?. Funct Ecol 2(2): 131-139.

2. Evenden ML, Silk PJ (2016) The influence of Canadian research on semiochemical-based management of forest insect pests in Canada. Can Entomol 148: 170209.

3. Bruce TJA, Wadhams LJ, Woodcock CM (2005) Insect host location: a volatile situation. Trends Plant Sci 10(6): 269-274.
4. Nordlund DA, Jones RL, Lewis WJ (1981) Semiochemicals. Their Role in Pest Control. John Wiley and Sons, New York, pp: 306.

5. Reddy GVP, Cruz ZT, Bamba J, Muniappan R (2005) Development of a semiochemical-based trapping method for the New Guinea sugarcane weevil, Rhabdoscelus obscures. J Appl Entomol 129(2): 6569.

6. Blassioli Moraes MC, Borges M, Michereff MFF, Magalhaes DM, Laumann RA (2016) Semiochemicals from plants and insects on the foraging behaviour of Platygastridae egg parasitoids. Pesqui Agropecu Bras 51: 5 .

7. Witzgall P, Kirsch P, Cork A (2010) Sex pheromone their impact on pest management. J Chem Ecol 36(1): 80-100.

8. Hosking G, Clearwater J, Handiside J, Kay M, Ray J, et al. (2003) Tussock moth eradication- A success story from New Zealand. Int J Pest Manage 49(1): 17-24.

9. El-Sayed AM, Suckling DM, Wearing CH, Byers JA (2006) Potential of mass trapping for long-term pest man 7 agement and eradication of invasive species. J Econ Entomol 99(5): 1550-1564.

10. Meurisse N, Couillien D, Grégoire J (2008) Kairomone traps: a tool for monitoring the invasive spruce bark beetle Dendroctonusmicans (Coleoptera: Scolytinae) and its specific predator, Rhizophagus grandis (Coleoptera: Monotomidae). J Appl Ecol 45(2): 537548.

11. Trematerra $P$ (2012) Advances in the use of pheromones for stored-product protection. J Pest Sci 85(3): 285-299.

12. Cardé RT, Minks AK (1995) Control of moth pests by mating disruption: successes and constraints. Annu Rev Entomol 40: 559-585.

13. Mauchline AL, Herve MR, Cook SM (2018) Semiochemical-based alternatives to synthetic toxicant insecticides for pollen beetle management. Arthropod Plant Interact 12(6): 835-847.

14. Gut LJ, Stelinski LL, Thomson DR, Miller JR (2004) Behavior-modifying chemicals: prospects and constraints in IPM. In: Koul O, Dhaliwal GS, Cuperus G, (Eds.), Integrated pest management: potential, 


\section{International Journal of Zoology and Animal Biology}

constraints, and challenges. CABI Press, Wallingford, United Kingdom, pp: 73-121.

15. Welter SC, Pickel C, Millar J, Cave F, Van Steenwyk R, et al. (2005) Pheromone mating disruption offers selective management options for key pests. Calif Agric 59: 16-22.

16. Cork A, Basu SK (1996) Control of the yellow stem borer, Scirpophagaincertulas (Walker) (Lepidoptera: Pyralidae) by mating disruption with a PVC resin formulation of the sex pheromone of Chilo suppressalis, in India. Bull Entomol Res 86(1): 1-9.

17. David H, Nesbitt BF, Easwaramoorthy S, Nandagopal V (1985) Application of sex pheromone in sugarcane management. Proc Natl Acad Sci 94(3): 333-339.

18. Rochat D, Malosse C, Lettere M, Ducrot PH, Zagatti $\mathrm{P}$, et al. (1991) Male-produced aggregation pheromone of the American palm weevil, Rhynchophorus palmarum (L.) (Coleoptera: Curculionidae): collection, identification, electrophysi-ological activity and laboratory bioassay. J Chem Ecol 17(11): 12211230.

19. Beauhaire J, Ducrot PH, Malosse C, Rochat D, Ndiege IO, et al. (1995) Identification and synthesis of sordidin, a male pheromone emitted by Cosmopolites sordidus. Tetrahedron Lett 36(7): 1043-1046.

20. Miller JR, McGhee PS, Siegert PY, Adams CG, Huang J, et al (2010) General principles of attraction and competitive attraction as revealed by large-cage studies of moths responding to sex pheromone. Proc Natl Acad Sci USA 107(1): 22-27.

21. Cork A, Alam SN, Srinivasan K, Das CS, Ghosh GC, et al. (2005) Development of pheromone trap system for eggplant borer, Leucinodes orbonalis in South Asia. National Symposium on Recent Advances in Integrated Management of Brinjal Shoot and Fruit Borer, pp: 25-28.

22. Tamiru A, Khan ZR (2017) Volatile semiochemical mediated plant defense in cereal: A novel strategy for crop protection. Agronomy 7: 58.

23. Khan ZR, Midego CAO, Bruce TJA, Hooper AM, Pickett JA (2010) Exploiting phytochemicals for developing a push-pull crop protection strategy for cereal farmers in Africa. J Exp Bot 61(15): 4185-4196.
24. El-Sayed AM, Suckling DM, Byers JA, Jang EB, Wearing CH (2009) Potential of "Lure and Kill" in long-term pest management and eradication of invasive species. J Econ Entomol 102(3): 815-835.

25. Mensah RK (1996) Suppression of Helicoverpa spp. oviposition by use of natural enemy food supplements "Envirofeast". J Aust Entomol Soc 35(4): 323-329.

26. Cook SM, Khan ZR, Pickett JA (2007) The use of 'push-pull' strategies in integrated pest management. Annu Rev Entomol 52: 375-400.

27. Bhattacharyya M (2017) The push-pull strategy: A new approach to the eco-friendly method of pest management in agriculture. J Entomol Zool Stud 5(3): 604-607.

28. Pickett JA, Woodcock CM, Midega CAO, Khan ZR (2014) Push- pull farming system. Curr opin biotechnol 26: 125-132.

29. Agelopoulos N, Birkett MA, Hick AJ, Hooper AM, Pickett JA (1999) Exploiting semiochemicals in insect control. Pestic Sci 55(3): 225-235.

30. Khan ZR, Midega CAO, Wadhams LJ, Pickett JA, Mumuni (2007) Evaluation of Napier grass (Pennisetumpurpureum) varieties for use as trap plants for the management of African stemborer (Busseolafusca) in a 'push-pull' strategy. Entomol Exp Appl 124(2): 201-211.

31. Midega CAO, Pittchar JO, Pickett JA, Hailu GW, Khan ZR (2018) A climate- adapted push pull system effectively control fall armyworm, Spoderptera frugiperda (JE Smith), in maize in East Africa. Crop Prot 105: 10-15.

32. Brightwell R, Dransfield RD, Kyorku CA (1991) Development of a low-cost tsetse trap and odour baits for Glossinapallidipesand G. longipennisin Kenya. Med Vet Entomol 5(2): 153-164.

33. Byers JA, Schlyter F, Birgersson G, Francke W (1990) E-myrcenol in Ipsduplicatus: an aggregation pheromone component new for bark beetles. Experientia 46(11/12): 1209-1211. 